\title{
Estimating the Capacity of a Curbside Bus Stop with Multiple Berths Using Probabilistic Models
}

\author{
Tian LUO*, Jingshuai YANG
}

\begin{abstract}
Capacity estimation of a curbside bus stop is essential to evaluation of its operation, reliability and performance. Arrival buses and served buses will form an overflow queue and an interlocking queue in loading areas with high frequencies. Therefore, bus stop blockage may reduce the stop capacity. The capacity of a bus stop is modelled as a function of the blockage probability, the arrival of buses, and the service time, while considering the no-overtaking principle and allowable-overtaking principle. This study aims to estimate the capacity, minimum arrival time and maximum service time based on the blockage probability and number of berths. The results indicate that congestion can be effectively alleviated by increasing the number of berths when the demand for loaded buses is low due to the significantly changing probability threshold for a NO stop. A congestion and stopping principle is important when multiple bus routes converge at the same bus stop. By combination with an actual case, an optimal overtaking principle is obtained using a computer program written in the MATLAB environment. The developed methodology can be practically applied to determine the loading principle and designated stopping berths for multi-route buses.
\end{abstract}

Keywords: blockage probability; bus stop and berth; capacity; logistics; performance analysis; public transit

\section{INTRODUCTION}

Bus stops represent a key type of bottleneck that leads to significant capacity drops and delays in bus system performance $[1,2]$. Urban public transit systems perform an essential function regarding the mobility of citizens in metropolitan areas around the world [3, 4]. The stopping demands of different types of stops and various road conditions lead to the need for greater divergence and randomness. In this manner, bus behavior and queue discipline are characterized by tasks with high complexity. In general, the shape and size of bus stop and its capacity are restrained by road cross section and the adjacent objects (e.g. sidewalks, buildings). This research focuses on the curbside bus stop, which includes all activities within an isolated stop, such as bus queuing, arrival loading areas, boarding and alighting of passengers, and departure. The capacity of curbside bus stops with multi-berth and tandem sub-stops is important for the accessibility and reliability of public transport, and thus, it has become increasingly important to continuously improve the service level of bus stops [5]. Blockage probability and queue discipline could be key performance indicators for improving bus stop capacity since the goal of such stops is to function effectively with minimum delays and blockages. Thus, a capacity model described by "Highway Capacity Manual 2000" (HCM) has been used as a foundation for this study. The model includes the average dwell time, coefficient of variation, clearance time, effect of traffic signals in front of the bus stop, and probability of bus queue formation behind the bus stop [6]. Based on the HCM model, a model considering the blockage probability, no-overtaking principle (NOP) and allowable-overtaking principle (AOP) will define the capacity of a curbside bus stop.

The remainder of this paper is organized as follows. In Section 2, we discuss the relevant literature. In Section 3, the capacity models for the NOP and AOP are developed. In section 4 , the models are analyzed for multiple berths based on NOP and AOP capacities. In Section 5, we verify the effectiveness of the proposed methods using an idealized bus stop and a real bus line in Xi'an, China. Finally, Section 6 draws conclusions, describes the future work of the study and discusses the practical implications for bus operation.

\section{LITERATURE REVIEW}

Two categories of estimating bus stop capacities are available in the literature. First, analytical models are used to estimate capacity with a steady-state formula [7]. The estimation of bus stop capacity is based on the HCM2000 [6].

Fernandez \& Planzer [8] presented that the HCM model tends to underestimate bus stop capacity compared to the results of other field studies. Fernandez further mentioned divided bus stops. A divided bus stop contains berths that are separated to reduce bus interference and increase bus capacity. The capacity of the downstream stop should be added to the reduced capacity of the upstream stop [9]. Al-Mudhaffa calculated the bus stop capacity considering the scheduling and design of terminals, estimating the maximum number of bus departures. In the long term, deeper analysis will be required, e.g., considering the need for a safety zone behind reversing buses and the demand for dedicated loading areas [7]. Gu presented a method to estimate the capacity as functions of not only, but also bus arrival process and bus service time distribution. He developed a model taking into account the bus arrival pattern via variations in bus headways to estimate the capacities of isolated curbside bus stops. According to the authors, this model can be used to predict the amount of variation in bus headways and bus service times that can diminish the stop capacity [10]. To further this research, $\mathrm{Gu}$ modelled the bus stop capacity using the number of berths, variations in bus headways and allowable bus flows [11].

Hisham developed an approach towards capacity estimation considering influence of traffic blockage, interference between buses and signalized intersections. The proposed modified model provides a greater understanding of bus stop operation based on Quality of Service Manual (TCQSM, 2013), which is useful to transit analysts in improving bus stop operations and providing better service reliability [12]. Matias Navarro proposed a 
model for estimating the capacity of curbside bus stops on bus corridors, which measures the level of service using the queue time as a metric. They considered the effects of overtaking lanes and downstream traffic lights. The capacity is influenced by the number of berths, the locations of bus stops along a street block, and the implementation of overtaking lanes [13]. Wang Chao proposed a method for estimating the capacity of bus stops isolated from the influences of traffic signals and other bus stops. Stochastic queuing models for both single-berth and multi-berth stops were developed to estimate the bus stop capacity and bus delay time [14]. Due to the complexity of the problem, most of these early studies did not involve the relationship between blockage probability and queue. Yet, above papers do little to quantify these influences.

Bus stop operation simulation software has also addressed the problem of capacity estimation. Gibson presented IRENE [15]. The simulation program analyzes bus stop capacity. Based on boarding and alighting passengers, the number of berth, the bus size, and bus arrivals, the output variables are the capacity, queue waiting time and dwell time. This approach considers an isolated bus stop with multiple-berths and an overtaking discipline for curbside bus stop. Under these conditions, a bus can enter the stop area only if the upstream berth is free. The stop area can be distinguished as being in two states: unblocked and blocked. Fernandez presented the PASSION system. The simulation program defined different routes of public transport that can have heterogeneous demands. By analyzing four different types of bus stop exits, the bus stop capacity is estimated. PASSION is developed as part of broader studies on the interactions between buses, passengers and traffic at bus stops [16].

There are overtaking rules and bus queue disciplines in this literature. Among the driving maneuvers, bus overtaking is one that is commonly observed in real life. Such a phenomenon can take place between stops or at bus stops.

Overtaking rules were discussed in 1974 by Bly \& Jackson. The mean passenger waiting time was decreased by $1.14 \%$ by the simulation of a particular bus route [17]. Regarding bus queue disciplines, it is widely believed that when all other factors are equal, an allowable overtaking strategy always provides a higher allowable bus flow than does a NOP stop [18, 19]. Golshani considered the relationship between three different patterns and the waiting time. When overtaking is prohibited, a trailing bus has to spend some idle time waiting behind a late bus. It is well known that a late bus becomes increasingly late, and as a result, bunching will tend to affect the buses behind, making a larger bunching effect. If overtaking is allowed, both types of buses spend less time at stops, since in general, there is no idle-wait time, and hence, the journey time should be shorter. The three different patterns are neither overtaking nor queue sharing permitted, overtaking prohibited but queue sharing permitted, and overtaking permitted [20]. The above papers focused on the relationship between the waiting time and overtaking rules, and the capacity is an important factor affecting the operational reliability and has not been considered, e.g. overtaking principles, berth, arrival time and dwell time.
In the study, the impacts of NOP and AOP capacity principles due to blockage probability at a stop are analyzed.

\section{METHODOLOGY}

This section presents the models and analysis methods. The capacity model is described according to three key components of a curbside bus stop: the size of the berth, the bus behavior, and the bus arrival and service times. A probabilistic model is developed to estimate the minimum arrival time and maximum service time under the AOP.

The bus stop capacity is dependent on the single-berth and multi-berth capacities of the HCM. The number of buses that can be served depends on the dwell time, which represents the average amount of time a bus is stopped at the curb to allow passenger movement, including the time required to open and close the doors. Another important factor is the behavior of the bus at the upstream berth specifically, whether or not it can overtake downstream buses. The third factor is the bus arrival time and service time at the berth, which are defined as the blockage probability indicating that one bus will arrive upstream of the waiting area while another bus is already occupying it. The combination of these three factors determines the capacity of the buses occupying the loading area.

In the highway capacity manual HCM2000, in chapter 27 , the estimated capacity of a single bus stop is calculated as follows [6]:

$B_{S}=N_{\mathrm{eb}} \frac{3600(g / d)}{t_{c}+(g / d) t_{d}+Z_{a} c_{v} t_{d}}$

where, $B_{S}$ is the capacity of an on-street bus stop, buses/h; $g$ is the green plus amber time at a downstream traffic signal, $\mathrm{s} ; d$ is the cycle time at the downstream traffic signal, $\mathrm{s} ; t_{c}$ is the clearance time between successive buses, $\mathrm{s} ; t_{d}$ is the passenger dwell time at the bus stop, $\mathrm{s} ; c_{v}$ is the coefficient of variation of the passenger service time, $\mathrm{s} ; Z_{a}$ is the one-tail variant of the normal distribution associated with the probability that a queue will not form behind the bus stop; and $N_{\mathrm{eb}}$ is the effective number of berths out of actual berths.

\subsection{Capacity Considering NOP and Blockage Probability}

The NOP for bus queuing involves systems with loading areas, i.e., a bus can use any empty berth without being blocked by buses that are occupying downstream berths. The efficiency of a berth area mainly depends on the dwell time of buses in the first berth. Upon reaching an upstream area at a stop, a bus will enter the stop when the first upstream berth is vacated, advance until encountering either an occupied berth or the most downstream berth of the stop to serve the boarding and alighting passengers, and eventually re-emerge in the community traffic flow. For a NOP bus stop, the following principles should be obeyed:

(1) Buses at an upstream berth (i.e., the first berth) are not allowed to overtake other buses dwelling at a downstream berth (i.e., the last berth) to exit the stop, as shown in Fig. 1 and 
(2) A queued bus cannot overtake any downstream bus to enter an empty berth.

\subsubsection{Overflow and Interlocking Probability for Multiple Berths}

Bus overflow and the interlocking phenomenon may frequently lead to blockage at a curbside bus stop. Bus overflow is focused primarily on isolated bus stops, so bus operations are usually not affected by community vehicles and traffic signals. The interlocking phenomenon occurs at isolated bus stops where bus operations are indeed affected by the community traffic flow, as shown in Fig. 1.

The overflow of a bus stop may be attributed to the queue waiting in upstream areas and buses dwelling in the downstream areas, including service buses. A critical issue to be solved for isolated bus stops is instances in which bus operations are not affected by upstream stops and the community traffic flow. In the NOP scenario, the dwell time at the most downstream stop exceeds the service times in the other berths.

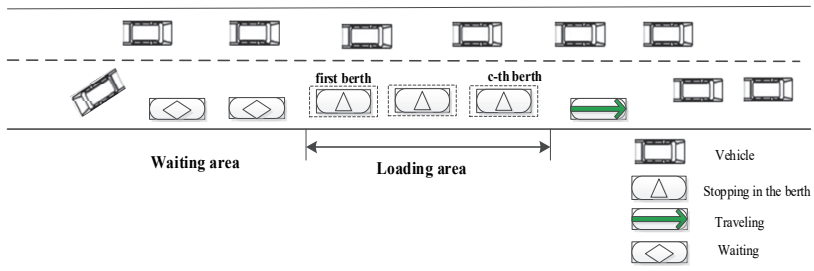

Figure 1 Illustration of the loading areas and bus statuses for the NOP

To clarify this problem, a set of variables describing the vehicle on this single route are defined. $q_{b}$ is the waiting buses in the upstream area; $n$ is arrival buses; $E(n)$ is average arrival buses; $p_{o}$ is the maximum probability threshold of overflow; $c$ is the number of berths of the curbside bus stop.

To introduce the overflow, we will discuss the operational issue with ac-berths bus stop.

Assumption:

(1) No empty berth awaits the arrival of a bus, and all berths are busy.

(2) There are more than $c$ arrival buses $n(n>c)$ are waiting in the upstream area.

(3) The first bus at the $c$-th berth accelerates away from the berth, permitting the subsequent bus to enter the berth. Fig. 1 illustrate the stages of bus stop operations.

During the arrival of the bus in turn, the berth is entirely occupied and a queued bus waits to enter the stopping area, making overflow occurrence a certainty. An upper partial moment (UPM) concept [21] incorporates this aspect into the blockage probability constraints. It is demonstrated in appendix A.

The maximum probability threshold of overflow in the upstream berth is expressed by the following equation:

$\operatorname{Pr}\left(q_{b} \geq E(n)\right) \leq 1 / p \leq 1 / q^{*}$

$p_{0}=1 / q^{*}$

The constraints are: s.t. $\left\{\begin{array}{c}\frac{q_{b}-E(n)}{\rho(1, E(n))} \geq q^{*} \\ E(n) \geq c\end{array}\right.$

$p=(E(n)-t) / \theta(\alpha, t)$

With $\theta(1, E(n))=[\rho(1, E(n))] \geq 0$

For a continuous case, where, $t$ is a reference level of variable $n ; \alpha$ is a constant greater than zero, and $\alpha=1$.

Under highly congested scenarios, the dwell time can be very long due to the difficulty of finding an acceptable gap, which not only causes significant delays but also results in bus stop capacity issues (because the waiting area is occupied; thus, arriving buses cannot enter the loading area).The interlocking phenomenon of the bus stop may affect the bus inflow and even the bus discharge flow. It is the result of super saturation of the loading area and is an extreme phenomenon of road saturation. Interlocking blocks the buses in the upstream area and the traffic flow in the adjacent lane, reducing the capacity of the stop section. When overtaking is not allowed, the phenomenon occurs due to the arrival of a number of vehicles, forming a long queue beyond the designed length of the stop and occupying the adjacent motorway. The phenomenon of locking is the result of over-saturation in the area, which causes delays of public transport vehicles, reduces the traffic capacity of the adjacent motor vehicle lane, and causes the buses and other community vehicles to obstruct each other to form a "bottleneck" in the road section, as shown in Fig. 2. The interlocking phenomenon may occur mainly in heavily congested scenarios, which may lead to more blockage of traffic occurring in the lane next to the shoulder (the queue also affects the buses entering the stop). The bus at the berth remains there waiting for an available gap in the traffic stream.

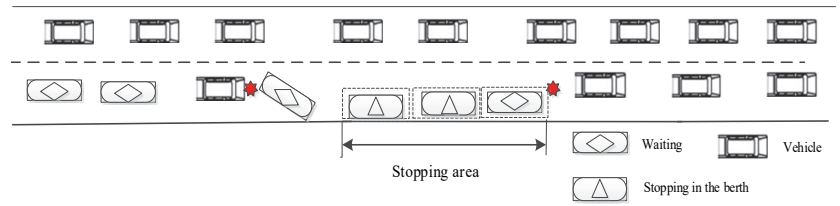

Figure 2 Interlocking between buses and vehicles

When there is an acceptable gap, the bus in the downstream-most berth will merge into the traffic flow of the adjacent lane.

Thus, the probability of interlocking for a curbside bus stop is expressed by the following equation:

$\eta=\frac{1}{q^{*}} \cdot p\left(h_{a}<\tau_{b}\right)$

where, $\eta$ is the probability of interlocking; $\tau_{b}$ is the critical headway between vehicles and the bus in the last berth, s; and $h_{a}$ is the headway of the traffic in the lane next to the shoulder between the bus in the most downstream berth and community vehicles, $\mathrm{s}$. 


\subsubsection{Capacity for a NOP Bus Stop}

For a NOP stop with berths, let $T_{(c)}=\max \left\{s_{n}\right\}, n=(1$, $2, \ldots, c)$ be the service time of a bus in the upstream berth, where $S_{n}$ is the service time of the $n$-th bus on the last upstream berth.

All $S_{n}$ values are independent variables, and the distribution function is $F_{s}(t)$ [11]. We have:

$$
\begin{aligned}
& \begin{aligned}
F_{T(c)}(t) & =P(T(c) \leq t)=P\left(s_{n} \leq t, n=1,2, \ldots, c\right) \\
& =\prod_{n=1}^{c} P\left(s_{n} \leq t\right)=\prod_{n=1}^{c} F_{s}(t)=\left[F_{s}\left(t_{c}\right)\right]^{c}
\end{aligned} \\
& E\left(t_{c}\right)=\int_{0}^{\infty}\left(1-\left(F_{s}(t)\right)^{c} \mathrm{~d} t\right.
\end{aligned}
$$

The rate at which buses discharge from the NOP stop [11], $Q_{\mathrm{NO}}$ in buses/h, is defined as follows:

$$
Q_{\mathrm{NO}}=\frac{c}{\int_{0}^{\infty}\left(1-\left(F_{s}(t)\right)^{c} \mathrm{~d} t\right.}
$$

The capacity of the NOP stop based on the overflow probability, $C_{N O}$, buses $/ \mathrm{h}$, is:

$$
\begin{aligned}
& C_{\mathrm{NO}}=\varepsilon_{1} \cdot p_{o} \cdot Q_{\mathrm{NO}} \cdot \frac{3600}{T_{\mathrm{NO}}}+B_{S}\left(1-\varepsilon_{1} \cdot p_{o}\right) \\
& \varepsilon_{1}= \begin{cases}1 & 0<p_{o} \leq 1 \\
0 & \text { otherwise }\end{cases}
\end{aligned}
$$

The capacity of the NOP stop based on the interlocking probability, $C_{\mathrm{NO}}^{\prime}$, buses $/ \mathrm{h}$, is:

$$
C_{\mathrm{NO}}^{\prime}=\varepsilon_{2} \cdot \eta \cdot Q_{\mathrm{NO}} \cdot \frac{3600}{T_{\mathrm{NO}}}+B_{S}\left(1-\varepsilon_{2} \cdot \eta\right)
$$

$\varepsilon_{2}=\left\{\begin{array}{lc}1 & 0<\eta \leq 1 \\ 0 & \text { otherwise }\end{array}\right.$

\subsection{Capacity Considering AOP and Blockage Probability}

We first consider the AOP. A bus can enter a stop freely when its curb lane is accessible and the first berth is not occupied. Buses in an upstream berth are allowable to overtake other buses dwelling in a downstream berth to exit the stop. A queued bus may overtake any downstream bus to enter an empty berth based on the traffic flow of the curb lane. The principle of prioritized arrival for the buses is first come, first served (FCFS), wherein serviced buses leave the stop. Under the AOP, a bus can reach the loading area as long as there is a vacant berth. According to queuing theory, the bus arrival and departure behaviors are in accordance with the overtaking principle, followed by the FCFS principle for a for multi-servicer. The probability of forming a long queue and overflow phenomenon is lower over a long period of time for the AOP than for the NOP.
In this paper, we propose reconsidering the queue theory model (e.g., M/M/c) [22], during which we model and simulate the blockage probability with the objective of evaluating the bus stop capacity.

The $\mathrm{M} / \mathrm{M} / \mathrm{c}$ is a variation of the classical queue in which the service is provided by $c$ berths operating independently of each other to achieve the AOP and an accessible curb lane. This modification is natural since if the mean arrival rate is greater than the service rate, the system will not be stable, indicating that the number of berths should be increased.

The system stability condition [23] is:

$\rho_{c}=\frac{\lambda}{c \mu}=\frac{\rho}{c}<1$

where, $\lambda$ is arrival bus intensity; $\mu$ mean service time on a certain berth, $n$ is arrival bus; $\rho$ is service intensity; $\rho_{c}$ is service intensity per berth. $p_{0}$ is the probability of no any bus. $p_{n}$ is the probability that at least $n$ buses in loading areas.

$P_{n}=\left\{\begin{array}{l}\frac{\rho^{n}}{n !} p_{0}, \quad n=1,2, \ldots, c \\ \frac{\rho^{n}}{c ! c^{n-c}} p_{0}, \quad n \geq c\end{array}\right.$

$P_{0}=\left[\sum_{n=0}^{c-1} \frac{\rho^{n}}{n !}+\frac{\rho^{c}}{c !\left(1-\frac{\rho}{c}\right)}\right]^{-1}$

$P_{0}=\frac{c !\left(1-\frac{\rho}{c}\right) P(n \geq c)}{\rho^{c}}$

Since blocking occurs only when $n \geq c$ according to Eq. (11) and Eq. (12), the blockage rate $p_{s}$ is:

$$
p_{s}=P(n \geq c)=\frac{\rho^{c}}{\rho^{c}+c !\left(1-\frac{\rho}{c}\right) \sum_{n=1}^{c-1} \frac{\rho^{n}}{n !}}
$$

The rate at which discharge from the AOP stop is:

$Q_{\mathrm{AO}}=\frac{c}{E(S)}$

where, $S$ is the service time in seconds, s.

The capacity of an AOP stop, $C_{A O}$, buses/h, is defined as follows:

$C_{\mathrm{AO}}=p_{s} \cdot \frac{3600}{T_{\mathrm{AO}}} \cdot Q_{\mathrm{AO}}+B_{s}\left(1-p_{s}\right)$

where, $T_{\mathrm{AO}}$ is the time per cycle in second, $\mathrm{s}$. 
Considering blockage probability, the capacity of an AOP stop is estimated based on queue model.

\section{ANALYSIS}

\subsection{The NOP Performance of a Multi-Berth Stop}

The threshold of the blockage probability ranges from the loading demands of 100 to $600 \mathrm{buses} / \mathrm{h}$, as shown in Fig. 3. When the arriving buses follow a Poisson distribution, the stopping demand is less than 400 buses $/ \mathrm{h}$, and the capacity increases upon adding berths. When the loading demand is more than $400 \mathrm{buses} / \mathrm{h}$, the stop is in a high-load state, which is associated with heavy congestion scenarios. At the same time, due to the NOP, the bus dwell time in the first upstream berth affects the subsequent queuing buses; thus, the effective utilization of the berth is smaller.

To show the effect of adding berths, the maximum threshold value of the blockage probability versus the number of berths is shown in Fig. 3. The maximum threshold decreases with additional berths. Therefore, congestion may be alleviated by increasing the number of berths according to the significant change of the blockage probability. However, the maximum threshold does not change significantly when the demand is more than 400 buses $/ h$. Upon adding berths in this case, the resulting effect does little to ease the blockage problem.

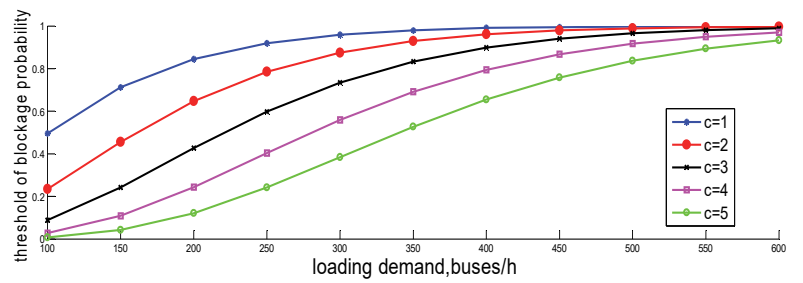

Figure 3 Threshold of the blockage probability

\subsection{The AOP Performance of Multiple Berths}

When the arriving buses follow a Poisson distribution, the service time follows a negative exponential distribution according to the number of different berths, the impact of the average arrival time on the blockage probability, and the impact of the average service time on the blockage probability analysis.

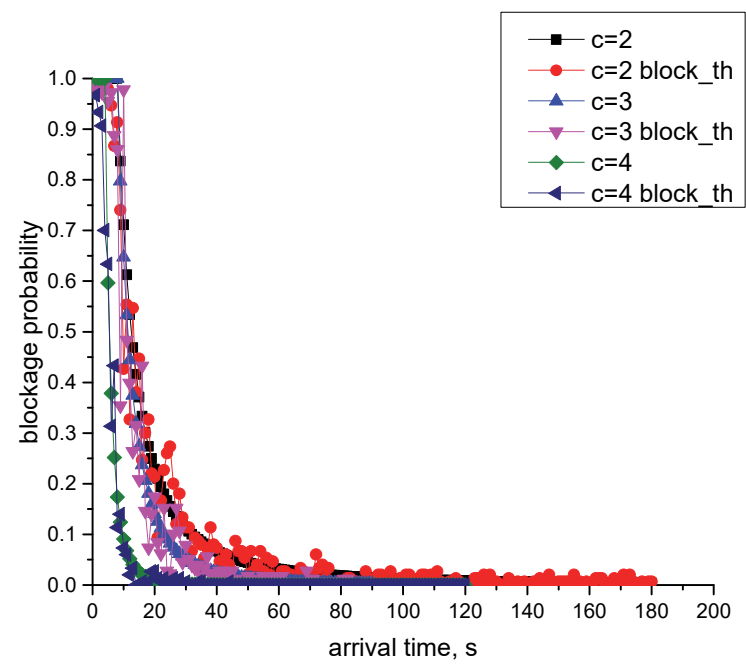

Figure 4 Arrival time versus blockage probability for a multi-berth bus stop
Fig. 4 shows the blockage probability versus the average arrival time to further illustrate the effect of adding berths to a curbside stop. The variable block th represents theoretical value of the blockage probability. The other lines and symbols represent the simulated results. Fig. 4 shows that the blockage probability decreases with increasing arrival times. Comparisons between the simulated values and theoretical values indicate that the bus stop service level decreases the stop's blockage probability in serving buses.

Assume that the number of buses arriving during peak hours is 150 buses/h. The average arrival time with added berths is less than $36 \mathrm{~s}, 28 \mathrm{~s}$ and $17 \mathrm{~s}$ for $c=2,3$ and 4, respectively, and the blockage probability decreases considerably. When the arrival time is more than $36 \mathrm{~s}, 28 \mathrm{~s}$ and $17 \mathrm{~s}$, the change in the blockage probability tends to be gentle. The simulated trend is consistent with the trend of the theoretical blockage probability.

The dwell time and blockage probability of the stop increases with increasing service times.

Meanwhile, the average service time with added berths is more than $9 \mathrm{~s}, 17 \mathrm{~s}$ and $29 \mathrm{~s}$ for $c=2,3$ and 4, respectively, and the blockage probability increases considerably in Fig. 5 . The simulated trend of the blockage probability agrees with that calculated by the AOP model.

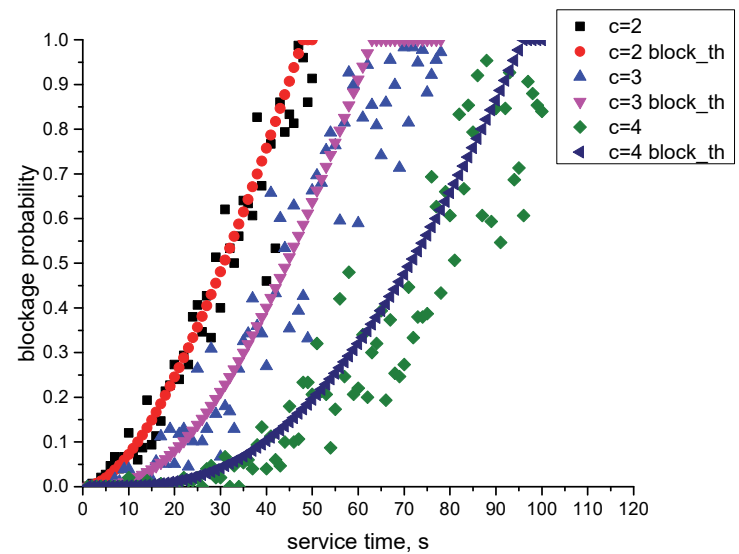

Figure 5 Service time versus blockage probability for a multi-berth bus stop

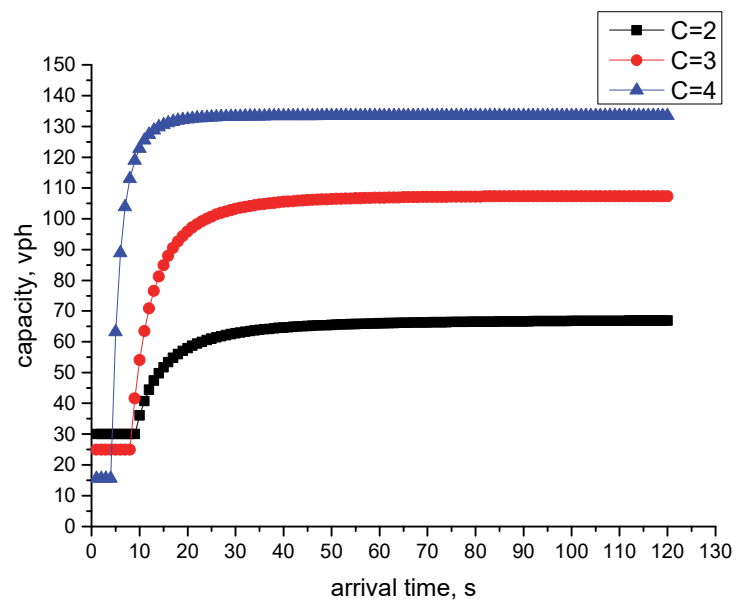

Figure 6 The AOP capacity and arrival time for a multi-berth stop

The average arrival time is less than $40 \mathrm{~s}, 30 \mathrm{~s}$ and 20 $\mathrm{s}$ upon adding berths, and buses in the first upstream berth wait in the queue for service. Therefore, the capacity increases with the increase of the arrival time. When the 
arrival time is greater than $40 \mathrm{~s}, 30 \mathrm{~s}$ and $20 \mathrm{~s}$, the capacity changes tend to be stable and can meet the demand, no longer resulting in long queues in Fig. 6. The maximum capacity drops are $7.5 \%, 6.1 \%$ and $5.2 \%$ for 2,3 and 4 berth stops that are lower than the HCM theoretical capacity. It is reason for considering blockage probability based on HCM model and principles.

The average service time with added berths is more than $9 \mathrm{~s}, 17 \mathrm{~s}$ and $29 \mathrm{~s}$ for $c=2,3$ and 4, respectively, the capacities are reduced by $5 \%, 15.2 \%$ and $6.6 \%$, the entire system is in a high-load state, and the bus waits and queues to enter loading area. Therefore, the arrival time is more than $36 \mathrm{~s}$; and the service time is less than $9 \mathrm{~s}$ for a 2-berth stop; the arrival time is more than $28 \mathrm{~s}$; the service time is less than $17 \mathrm{~s}$ for a 3-berth stop; and the arrival time is more than $17 \mathrm{~s}$ and, the service time is less than $29 \mathrm{~s}$ for a 4-berth stop in Fig. 7. The capacity can meet the service demand for a multi-berth curbside stop.

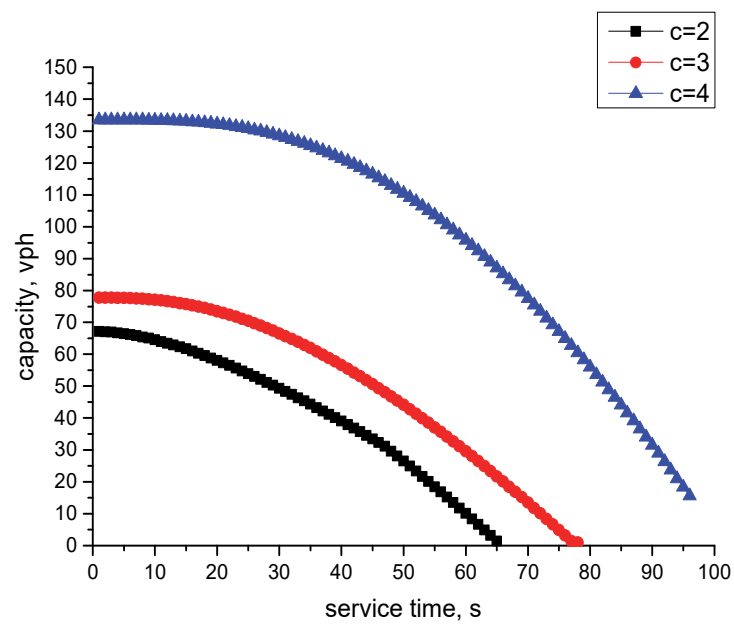

Figure 7 The AOP capacity and service time for a multi-berth stop

The capacity of stops was analyzed under the NOP and AOP. The capacity of every stop varies considerably due to the impact of the stopping demand, accommodating routes and bus lane style.

\subsection{Selection of the Loading Principle Based on Demand}

The AOP are influenced by factors, such as the capacity of the stop and curb lane, the number of buses arriving, internal congestion that occurs for different reasons, upstream queues and the number of serviced buses that have completed loading. Meeting these requirements enables supporting many arriving and stopping patterns of buses, as well as different exit conditions. For example, constant headways, critical headways, scheduled arrivals, the service of several lines with different frequencies, and bus bunching can be supported. In addition, the exit from the loading area can be completely free or partially obstructed by traffic conditions [24]. The exit can be controlled by blockage during certain times due to other buses ahead or in the curb lane.

Everything-has-two-coins. At the expense of high costs, it is not efficient or economic to build bus stops with more than three berths for high frequency buses [16]. Therefore, increasing the number of berths $(c>3)$ is not an effective way to improve the capacity for the NOP or the
AOP. For multi-line buses arriving at a stop, stopping is determined based on whether the maximum capacity of the stop satisfies the stopping demand $\left(N_{s}\right)$ of multi-line buses. Fig. 8 shows the flowcharts of the selection of the AOP, NOP and bus stop type.

The stopping demand exceeds the NOP capacity and HCM capacity, the congestion can be relieved by increasing the number of berths when $c<3$. When the demand is greater than the AOP capacity and $T_{s} \leq h_{a}$, the average headway of the adjacent lane allows the buses to cross at the downstream berth when they leave the stop. That is, the AOP is adjusted to increase the capacity by adding berths for $c<3$.

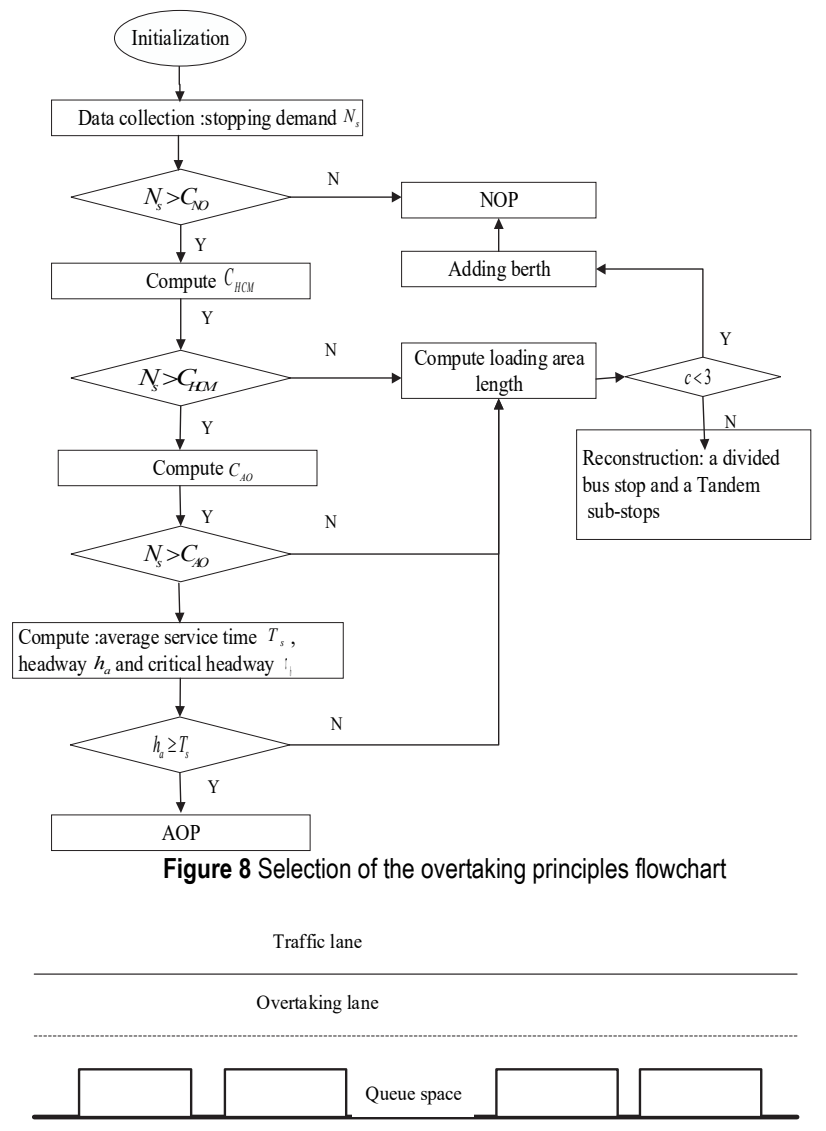

Figure 9 Recommended layout for divided bus stops

Table 1 Demand and supply capacity during peak hours for a curbside stop

\begin{tabular}{|c|c|c|c|c|c|c|}
\hline $\begin{array}{c}\text { Stop } \\
\text { number }\end{array}$ & $\begin{array}{c}\text { Bus } \\
\text { priority } \\
\text { lane }\end{array}$ & Berths & Routes & $\begin{array}{c}\text { Demand } \\
\text { / buses/h }\end{array}$ & $\begin{array}{c}\text { HCM } \\
\text { capacity } \\
\text { /buses/h }\end{array}$ & $\begin{array}{c}\text { NOP } \\
\text { capacity } \\
\text { / buses/h }\end{array}$ \\
\hline 1 & No & 2 & 13 & 100 & 86.7 & 58.3 \\
\hline 2 & No & 2 & 11 & 84 & 79.3 & 57.6 \\
\hline 3 & No & 3 & 23 & 178 & 118 & 87.3 \\
\hline 4 & No & 2 & 17 & 131 & 92.4 & 63.2 \\
\hline 5 & No & 2 & 28 & 216 & 89.9 & 62.4 \\
\hline 6 & Yes & 3 & 35 & 269 & 143 & 99.7 \\
\hline
\end{tabular}

When the demand for multi-line buses is greater than the AOP capacity, there are two methods for alleviating congestion and satisfying the demand for stopping. The first method depends on the road traffic flow, number of lanes, and length of allowable loading area. At peak times, an overtaking lane should be established. Second, when the current motorway cannot satisfy the capacity of community vehicles, the capacity can be increased by increasing the number of berths when using the AOP for $c$ $<3$. The number of berths is not less than 3 , if the time 
during which the bus in the upstream berth completes its service is less than the time spent in the outbound motorway, the bus in the upstream berth can leave the stop with the downstream bus. According to the loading demand and length of the loading area, curbside bus stops with multiple berths should be reconstructed into divided stops or tandem stops [25], as shown in Fig. 9. Bus stops constitute one potential interruption to smooth traffic flow, as this could easily affect buses. Therefore, the benefit of bus lanes and other priorities to offset the effects of traffic congestion are obvious [26]. So we need to see how we should examine bus stops for their impact on bus operations.

\section{CASE STUDY}

We studied 6 curbside bus stops with larger numbers of passengers and buses, with no bus priority lanes in stops from NO.1 to NO.6. The 6 stops are curbside stops with high passenger flows and a bus lane. Throughout the investigation, no buses were allowable to overtake a bus in the berth.

As shown in Tab. 1, Eq. (1) estimates a higher capacity than that achieved under the NOP. Considering the blockage probability and overtaking principle, the results indicate a higher capacity than that calculated using Eq. (7), indicating that the NOP has a negative influence on the capacity. Under the AOP, the arrival time, service time and capacity of two and three berths for six stops were analyzed, as shown in Figs.10, 11, 12 and 13.

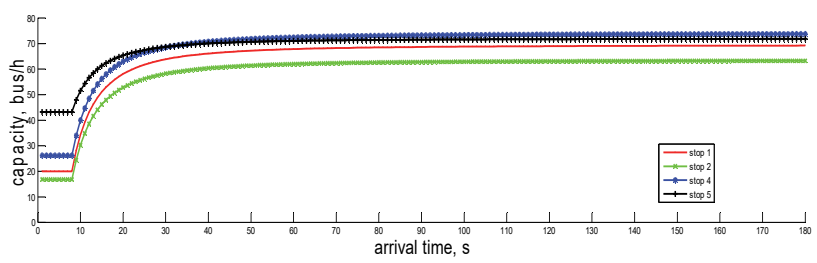

Figure 10 The AOP capacity versus arrival time for 2-berth stops

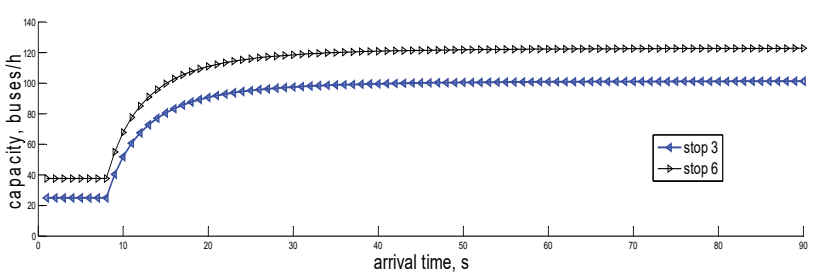

Figure 11The AOP capacity versus arrival time for 3-berth stops

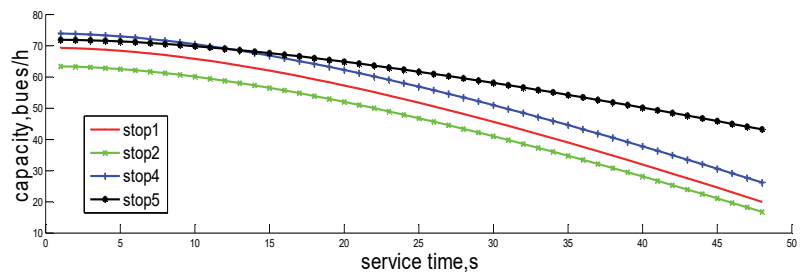

Figure 12 The AOP capacity versus service time for 2-berth stops

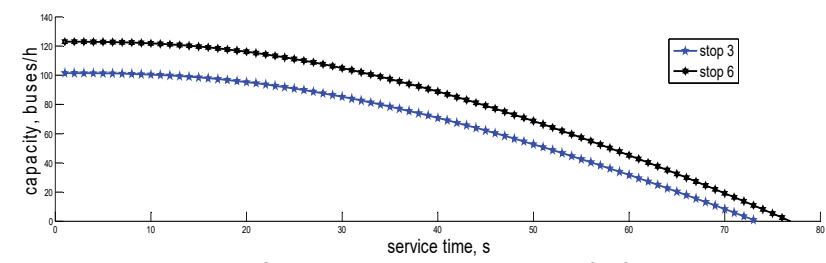

Figure 13 The AOP capacity versus service time for 3-berth stops
Assuming that the traffic flow of the curb lane allows the bus in an upstream berth to pass the buses in the downstream berths, then the threshold values of the minimum arrival time and maximum service time of the bus such that the bus stop does not cause congestion under ideal conditions can be obtained. When these two thresholds are exceeded, the stops become prone to congestion, resulting in significant reductions of capacity.

The analysis of the AOP indicates that $20 \%$ is the point at which the highest rate of change in the congestion probability occurs. Taking a congestion probability of $20 \%$ as an example, the minimum arrival interval and maximum service time thresholds are shown in Tab. 2.

It is assumed that these stops allow overtaking in an ideal road environment to analyze the capacity. The following conclusions can be drawn from the comparison of the arrival time, service time and maximum service time with a congestion rate of $20 \%$ :

(1) For the NO.1, NO.2 and NO.3 stops, if the service time of the vehicle is within the mean value of the service time, the congestion rate does not exceed $20 \%$, the operating conditions of the stops are good, and the overflow phenomenon of long upstream queues rarely occurs.

(2) For the NO.4, NO.5 and NO.6, the mean service time is greater than the maximum service time. Therefore, the stop capacity cannot meet the demand, and congestion is likely to occur.

(3) For two-berth stops, when the bus arrival time is less than $13 \mathrm{~s}$, the capacity is at a minimum, and the entire stop is highly loaded and prone to congestion. For the three berths at NO.3 and NO.6, when the arrival interval is less than $9 \mathrm{~s}$, the traffic capacity is the smallest and the stops are at full capacity, causing congestion.

(4) With an increase in the arrival time, the traffic capacity gradually increases, and the change in traffic capacity tends to be stable when the average arrival times of stop 1, stop 2 and stop 4 reach $27.1 \mathrm{~s}, 27.3 \mathrm{~s}$ and $30.1 \mathrm{~s}$, respectively. The arrival time of NO.5 is longer than 35.7 $\mathrm{s}$, and the change in the capacity of the terminals stabilizes.

(5) For the three-berth stops, at which are NO.3 and NO.6, more than $20 \%$ traffic congestion will easily occur when the arrival times are less than $17.4 \mathrm{~s}$ and $18.1 \mathrm{~s}$, respectively.

The analysis of six high-passenger flow stops is carried out to determine the demand of the stop, and the effective utilization rate, capacity and delay of the berth under the existing stop demand conditions are analyzed.

The berths of NO.5 and NO.6 are less efficient according to the analysis of the effective number of berths. Analysis of the traffic capacity shows that NO.3, NO.5 and NO.6 have high demands. The arrival time interval is small, and the reduction of the traffic capacity is greater. The NO.1 to NO.6 stops have high demands for docking, exceeding the capacity.

Therefore, the following solutions are proposed to improve the capacity.

(1) From the perspective of service level, the number of berths should be increased appropriately to reduce the waiting times of the vehicles in the upstream area.

(2) Since there is a bus lane at NO.6, adopting the AOP when the road conditions permit is recommended, so that the traffic capacity will be significantly greater than the 
traffic capacity of overtaking, which can be up to $11.2 \%$. For stations that do not have a bus lane, using the principle of allowing overtaking in cases where the outside lane has a large headway and road conditions permit is recommended.

(3) From the perspective of bus dispatching, controlling the arrival times and departure times of vehicles in one or multiple lines and allowing certain vehicles to let other buses to enter and leave the stop if road conditions permit is recommended to minimize situations in which the buses arrival interval is too small.

Table 2 The minimum arrival time and maximum service time for non-congestion under the AOP

\begin{tabular}{|c|c|c|c|c|}
\hline Stops & $\begin{array}{c}\text { Demand } \\
\text { / buses }\end{array}$ & $\begin{array}{c}\text { Average } \\
\text { service time / s }\end{array}$ & $\begin{array}{c}\text { Minimum } \\
\text { arrival time / s }\end{array}$ & $\begin{array}{c}\text { Maximum } \\
\text { service time / s }\end{array}$ \\
\hline 1 & 100 & 19.8 & 27.1 & 27.1 \\
\hline 2 & 84 & 20.2 & 27.3 & 31.7 \\
\hline 3 & 178 & 24.0 & 17.4 & 30.6 \\
\hline 4 & 131 & 21.7 & 30.4 & 21.3 \\
\hline 5 & 216 & 26.4 & 35.7 & 14.9 \\
\hline 6 & 269 & 23.6 & 18.1 & 20.3 \\
\hline
\end{tabular}

\section{CONCLUSION AND FUTURE WORK \\ 6.1 Conclusion}

It is essential to estimate capacity of a curbside bus stop for its operation, reliability and performance. Formulas are developed to predict the capacity, minimum arrival time and maximum service time for curbside bus stops according to the stopping principle while still maintaining the target service levels. The models can also be used to determine a stop's suitable stopping principle and the number of berths required to achieve a higher service level. The formulae use the blockage probability, which is modeled considering the NOP and AOP at curbside stops. Exact solutions were derived using the HCM model and a blockage probability model of the two disciplines. The model results corresponded well with the simulation results from the computer program constructed in the MATLAB environment. As a practical matter, our models offer improvements to evaluate bus stop capacities considering blockage probabilities and principles. Further, the models can be used to predict other parameters of a bus stop service level, such as the queue length, delay and loading area size at a stop.

This paper proposed two blockage probability models for the NOP and the AOP by explicitly taking real-life features into account. The key contribution of the NOP probability model is the formulation of capacity that considers the overflow of upstream waiting buses and subsequent interlocking at downstream berths at the same time. To allow for overtaking while minimizing the waiting time in the upstream area, we proposed a capacity model on a first-come-first-served and first leave principle to be combined with queue models, the blockage probability and the bus stop capacity in HCM.

We tested the performances of different combinations of berths and blockage models under various operational settings in the MATLAB simulation environment. The experiments underlined the importance of the introduced effects of the NOP and the AOP by revealing the performance improvements that had not been described in the literature previously.
We find that the maximum threshold decreases with adding berth for NOP. Therefore, congestion may be alleviated by increasing the number of berths according to a significant change of blockage probability. However, the maximum threshold does not change significantly when the demand is more than 400 buses/h. With adding berth, the effect does little to ease the blockage problem. AOP among buses decreases dwell time and improves service regularity, and the benefit is greater when loading demand is higher and the blockage probability of change is the highest.

Finally, we verify the effectiveness of the proposed methods through a case study in a real bus line in Xi'an City, and the results suggest that the new strategy is most beneficial for the high frequency transit service. Another interesting finding is that the congestion can be relieved by increasing the number of berths $(c<3)$, when the stopping demand is greater than the NOP capacity and HCM capacity. Vehicles overload on adjacent lane, so the capacity can be increased by increasing the number of berths when using the AOP for $c<3$. The loading demand is greater than predictive value on AOP capacity. Considering road section cross, traffic flow, loading space, sidewalk and buildings it is recommended to establish a variable bus priority lane for peak time. It is recommended to transform the curbside to a divided stop or tandem substops for $c>3$. Bus lanes and other priorities to offset the effects of traffic congestion are available.

\subsection{Future work}

This work is meant to model and illustrate the effects on capacity considering the blockage probability, berth, NOP and AOP for curbside bus stops. Assumptions can be relaxed to developing better, more realistic analytical models for bus stops. The work can be extended to stops that are affected by the limited overtaking principle (LOP). We are particularly interested in the results that would be obtained from these proposed models, e.g., road cross sections, bus stop types, stopping principles (NOP, AOP and LOP), random arrivals and dwell times that affect a stop's allowable bus flow. Considering such factors would require replacing constants with random parameters.

\section{Acknowledgments}

The research was sponsored by Funding for Scientific Research Projects of Universities in Gansu Province (2019A-143) and Shaanxi Natural Science Basic Research Project (2019JM-309).

\section{Appendix A}

A UPM is defined as

$$
\rho(\alpha, t)=\sum\left(x_{i}-t\right)^{\alpha} f\left(x_{i}\right), x_{i} \geq t
$$

For a discrete case, or

$$
\rho(\alpha, t)=\int_{t}^{+\infty}(x-t)^{\alpha} f(x) \mathrm{d} x
$$

For a continuous case where $t$ is a reference level of variable $x, \alpha$ is a constant greater than zero, $f\left(x_{i}\right)$ is a relative frequency function, and $f(x)$ is a probability density function. 
$\operatorname{Pr}(x \geq t+p \theta(\alpha, t)) \leq(1 / p)^{\alpha}$

With $\theta(\alpha, t)=[\rho(\alpha, t)]^{1 / \alpha} \geq 0$ and $p=(g-t) / \theta(\alpha, t)$, where $g$ is standard set for variable $x$. Using the above equation, $t+q^{*} \theta(\alpha, t) \leq g$ is sufficient to guarantee that $\operatorname{Pr}(x \geq g) \leq(1 / p)^{\alpha} \leq\left(1 / q^{*}\right)^{\alpha}$.

\section{Notations}

\begin{tabular}{|c|l|}
\hline Symbol & \multicolumn{1}{|c|}{ Description } \\
\hline$B_{s}$ & the capacity of an on-street bus stop, buses/h \\
\hline$d$ & the cycle time at the downstream traffic signal, $\mathrm{s}$ \\
\hline$t_{c}$ & the clearance time between successive buses, $\mathrm{s}$ \\
\hline$t_{d}$ & the passenger dwell time at the bus stop, $\mathrm{s}$ \\
\hline$c_{v}$ & the coefficient of variation of passenger service time, $\mathrm{s}$ \\
\hline$N_{\mathrm{eb}}$ & the effective number of berths out of actual berths \\
\hline$q_{b}$ & the waiting buses in the upstream area; \\
\hline$n$ & arrival buses \\
\hline$E(n)$ & average arrival buses \\
\hline$p_{o}$ & the maximum probability threshold of overflow \\
\hline$c$ & the number of berths of the curbside bus stop \\
\hline$\eta$ & the probability of interlocking \\
\hline$\tau_{b}$ & $\begin{array}{l}\text { the critical headway between vehicles and the bus in the last } \\
\text { berth, s }\end{array}$ \\
\hline$h_{a}$ & $\begin{array}{l}\text { headway of the traffic in the lane next to shoulder between } \\
\text { bus in the most-downstream berth and community vehicles, } \mathrm{s}\end{array}$ \\
\hline$S_{n}$ & the service time of the $n$-th bus on the last upstream berth, $\mathrm{s}$ \\
\hline$C_{\mathrm{NO}}$ & $\begin{array}{l}\text { the capacity of the NOP stop based on the overflow } \\
\text { probability, buses/h }\end{array}$ \\
\hline$C_{\mathrm{NO}}^{\prime}$ & $\begin{array}{l}\text { the capacity of the NOP stop based on the interlocking } \\
\text { probability, buses/h }\end{array}$ \\
\hline$\lambda$ & Mean arrival bus intensity, bus/min \\
\hline$\mu$ & mean service time on a certain berth, bus/min \\
\hline$\rho$ & service intensity \\
\hline$\rho_{c}$ & service intensity per berth \\
\hline$p_{0}$ & the probability of no any bus \\
\hline$p_{n}$ & the probability that at least $n$ buses in loading areas \\
\hline$Q_{\mathrm{AO}}$ & the rate at which discharge from the AOP stop,buses \\
\hline$p_{s}$ & the blockage rate for AOP \\
\hline$S$ & the service time, $\mathrm{s}$ \\
\hline$C_{\mathrm{AO}}$ & the capacity of an AOP stop, buses/h \\
\hline$T_{\mathrm{AO}}$ & the time per cycle, $\mathrm{s}$ \\
\hline & \\
\hline & \\
\hline$\rho^{\prime}$
\end{tabular}

\section{REFERENCES}

[1] Estrada, M., Ortigosa, J., \& Robusté, F. (2011). Tandem bus stop capacity. TRB $90^{\text {th }}$ Annual Meeting Compendium of Papers. Washington DC, USA: Transportation Research Board of the National Academies, 1747. Retrieved from http://amonline.trb.org/

[2] Chen, C., Cong, C., \& Xu, Y. (2012). Research on Urban Bus Stop Parking Capacity Reliability. Sustainable Transportation Systems: Plan, Design, Build, Manage, and Maintain, 217-225. https://doi.org/10.1061/9780784412299.0027

[3] Bordagaray, M., dell'Olio, L., Ibeas, A., \& Cecín, P. (2014). Modelling user perception of bus transit quality considering user and service heterogeneity. Transportmetrica $A$ : Transport Science, 10(8), 705-721. https://doi.org/10.1080/23249935.2013.823579

[4] Chang, H., Park, D., Lee, S., Lee, H., \& Baek, S. (2010). Dynamic multi-interval bus travel time prediction using bus transit data. Transportmetrica, 6(1),19-38. https://doi.org/10.1080/18128600902929591

[5] Jaiswal, S., Bunker, J., \& Ferreira, L. (2010). Influence of platform walking on BRT station bus dwell time estimation: Australian analysis. Journal of Transportation Engineering, 136(12), 1173-1179.

https://doi.org/10.1061/(asce)te.1943-5436.0000174
[6] HCM2000, H. C. M. (2000). Transportation Research Board. National Research Council, Washington, DC. Retrieved from http://onlinepubs.trb.org/

[7] Al-Mudhaffar, A., Nissan, A., \& Bang, K. L. (2016). Bus stop and bus terminal capacity. Transportation Research Procedia, 14, 1762-1771. https://doi.org/10.1016/j.trpro.2016.05.142

[8] Fernandez, R. \& Planzer, R. (2002). On the capacity of bus transit systems. Transport Reviews, 22(3), 267-293. https://doi.org/10.1080/01441640110106328

[9] Fernandez, R., Burgos, V., \& Cortes, C. E. (2007). Results of the microscopic modelling of traffic interactions at stops, junctions and roads for the design of bus rapid transit facilities. Association for European Transport and Contributors.

Retrieved from https://trid.trb.org/view/859888

[10] Gu, W., Li, Y., Cassidy, M. J., \& Griswold, J. B. (2011). On the capacity of isolated, curbside bus stops. Transportation Research Part B: Methodological, 45(4), 714-723. https://doi.org/10.1016/j.trb.2011.01.001

[11] Gu, W. (2012). Models of Bus Queuing at Isolated Bus Stops (Doctoral dissertation, UC Berkeley). Retrieved from https://search.proquest.com/docview/1081483598

[12] Hisham, F., Bunker, J. M., \& Bhaskar, A. (2018). Development of a modified bus stop capacity model. Transportation Research Board (TRB) 97th Annual Meeting, 7-11 January 2018, Washington DC. Retrieved from https://trid.trb.org/view/1495281

[13] Navarro, M., Riquelme, I., Muñoz, J. C., \& Moya, J. (2017). Capacity of Curbside Bus Stops Located on Bus Corridors, Considering Level of Service. Overtaking Lanes and a Downstream Traffic Signal, No.17-05730. Retrieved from https://trid.trb.org/view/1439278

[14] Wang, C., Ye, Z., Fricker, J. D., Zhang, Y., \& Ukkusuri, S. V. (2018). Bus Capacity Estimation using Stochastic Queuing Models for Isolated Bus Stops in China. Transportation Research Record, 0361198118777358. Retrieved from https://trid.trb.org/view/1495888 https://doi.org/10.1177/0361198118777358

[15] Gibson, J., Baeza, I., \& Willumsen, L. (1989). Bus-stops, congestion and congested bus-stops. Traffic engineering \& control, 30(6), 291-302. Retrieved from https://trid.trb.org/view/296139

[16] Fernández, R. (2010). Modelling public transport stops by microscopic simulation. Transportation Research Part C: Emerging Technologies, 18(6), 856-868. https://doi.org/10.1016/j.trc.2010.02.002

[17] Bly, P. H. \& Jackson, R. L. (1974). Evaluation of bus control strategies by simulation. Transfer European Review of Labour \& Research, 14(3), 399-418. Retrieved from https://trid.trb.org/view/1178846

[18] Papacostas, C. S. (1982). Capacity characteristics of downtown bus streets. Transportation Quarterly 36(4), 617630. Retrieved from https://trid.trb.org/view/188582

[19] Gardner, G., Cornwell, P. R., \& Cracknell, J. A. (1991). The performance of busway transit in developing cities. Transport and Road Research Laboratory, Overseas Unit. Retrieved from https://trid.trb.org/view/347895

[20] Golshani, F. (1983). System regularity and overtaking rules in bus services. Journal of the Operational Research Society, 34(7), 591-597. https://doi.org/10.1057/jors.1983.139

[21] Qiu, Z., Prato, T., \& Mccamley, F. (2001). Evaluating environmental risks using safety-first constraints. American Journal of Agricultural Economics, 83(2), 402-413. https://doi.org/10.1111/0002-9092.00165

[22] Allen, A. O. (2014). Probability, statistics, and queueing theory. Academic Press. https://doi.org/10.1016/c2013-0-10285-1

[23] Sigman, K. (2006). Queueing Theory. Encyclopedia of Actuarial Science. 
https://doi.org/10.1002/9780470012505.taq001

[24] Fernandez, R. (2001). A new approach to bus stop modelling. Traffic engineering \& control. Retrieved from https://trid.trb.org/view/587766

[25] Estrada Romeu, M. Á., Ortigosa, J., \& Robusté Antón, F. (2011). Tandem bus stop capacity. TRB 90th Annual Meeting Compendium of Papers DVD, 1-13. Retrieved from https://trid.trb.org/view/1092097

[26] Fernandez, R. \& Tyler, N. (2005). Effect of passenger-bustraffic interactions on bus stop operations. Transportation Planning and Technology, 28(4), 273-292.

https://doi.org/10.1080/03081060500247747

\section{Contact information:}

\section{Tian LUO}

(Corresponding author)

Lanzhou Institute of Technology, School of Automobile Engineering,

1st, Gongjiaping East Road, Qilihe District, Lanzhou, 730050, China

E-mail: Ityangliuan@163.com

\section{Jingshuai YANG}

Chang'an University, School of Automobile,

Middle-section of Nan'er Huan Road Xi'an, 710064, China

E-mail: jshyang@chd.edu.cn 